\title{
Characterisation of methicillin-resistant Staphylococcus aureus isolates by restriction endonuclease digestion of chromosomal DNA
}

\author{
J. ZOE JORDENS and LUCINDA M. C. HALL
}

Department of Medical Microbiology, The London Hospital Medical College, Turner Street, London E1 2AD

\begin{abstract}
Summary. Clinical isolates of Staphylococcus aureus from the London Hospital were characterised by genetic analysis of antibiotic-resistance determinants and by restriction endonuclease digestion of chromosomal DNA and compared with isolates from elsewhere in the UK. Restriction enzyme digestion of chromosomal DNA confirmed that a single strain of methicillin-resistant $S$. aureus (MRSA) persists at the London Hospital, although its antibiotic-resistance profile and plasmid carriage are not constant. Methicillin-sensitive isolates, on the other hand, each had readily distinguishable and unique DNA restriction patterns. The DNA restriction digest pattern of the London Hospital MRSA isolates was identical to that of "epidemic" (E) MRSA isolates from the Thames regions. By contrast, other MRSA isolates had DNA restriction patterns which differed from those of EMRSA isolates and from each other. These results confirm the discriminatory value of restriction pattern analysis as a typing method.
\end{abstract}

\section{Introduction}

Methicillin-resistant strains of Staphylococcus aureus (MRSA) are important nosocomial pathogens. Because they are usually resistant to many antimicrobial agents, treatment of infections caused by them is often difficult. MRSA were first reported in the UK in the early 1960s (Barber, 1961 ; Jevons, 1961). More recently there has been an upsurge of MRSA causing clinical problems in hospitals in the four Thames regions of the National Health Service (Townsend et al., 1984; King and Harvey, 1985). In a survey of isolates submitted to the Public Health Laboratory Service, Marples et al. (1986) reported that prominent among MRSA from the Thames regions was one strain with a particular phage-typing pattern, which they refer to as epidemic (E) MRSA because of its apparent spread between hospitals.

In the present study, clinical isolates of $S$. aureus from the London Hospital and elsewhere have been characterised by examining the patterns produced by restriction endonuclease digestion of chromosomal DNA, by antibiotic resistance patterns and by plasmic analysis.

\section{Materials and methods}

\section{Bacterial cultures}

Five MRSA isolates (for which the MIC of methicillin was $32 \mathrm{mg} / \mathrm{L}$ ), one MRSA isolate with intermediate resistance to methicillin (MIC $4 \mathrm{mg} / \mathrm{L}$ ), five other $S$. aureus isolates resistant to multiple antibiotics but sensitive to methicillin (ORSA), and five susceptible $S$. aureus isolates resistant to benzylpenicillin only (SSA) were examined. All had been isolated at the London Hospital (LH) from clinical specimens during 1985-86. Seven EMRSA isolates from other hospitals in the Thames regions and nine other MRSA isolates were kindly provided by $\mathrm{Dr} \mathrm{R}$. Marples of the Division of Hospital Infection, Central Public Health Laboratory, Colindale. S. aureus NCTC 6571, the "Oxford" staphylococcus, was included as a fully sensitive control. All LH isolates were stored at $-70^{\circ} \mathrm{C}$ in peptone water containing glycerol and glucose $1 \% \mathrm{w} / \mathrm{v}$ and subcultured by overnight incubation on blood agar immediately before use. All other isolates were stored on nutrient-agar slopes at room temperature. The antibiotic susceptibility of all isolates was tested by disk diffusion against benzylpenicillin, erythromycin, tetracycline, fucidin, gentamicin, methicillin, chloramphenicol, neomycin, vancomycin and clindamycin.

\section{Plasmid analysis}

Plasmids were extracted by the ultra-rapid method of Bennett et al. (1986) except that propan-2-ol replaced 
ethanol and was allowed to act for $30 \mathrm{~min}$ at $-20^{\circ} \mathrm{C}$ instead of $5 \mathrm{~min}$ in liquid nitrogen to precipitate DNA. These samples were analysed by electrophoresis at $100 \mathrm{~V}$ on gels of agarose $0.9 \%$ in a solution of $0.089 \mathrm{M}$ Tris, $0.089 \mathrm{M}$ boric acid, $0.002 \mathrm{M}$ EDTA (TBE). Well-characterised recombinant plasmids of $2 \cdot 7,4 \cdot 1,8 \cdot 5,14 \cdot 1$ and $20 \mathrm{~kb}$, produced in $E$. coli were used as molecular size markers. The size of plasmids greater than $20 \mathrm{~kb}$ could not be accurately determined by this method.

\section{Curing of resistance phenotypes}

Isolates nos. 1-5 and 17 (MRSA), and 7, 8 and 10 (ORSA), were incubated overnight in nutrient broth at $43^{\circ} \mathrm{C}$ or at $37^{\circ} \mathrm{C}$ in the presence of ethidium bromide $3 \mathrm{mg} / \mathrm{L}$, plated on non-selective medium, then replica plated on to medium containing appropriate antibiotics. Colonies which had lost a particular resistance phenotype were tested for plasmid carriage.

\section{Chromosomal DNA extraction and digestion}

Cultures incubated overnight in $10 \mathrm{ml}$ of brain heart infusion broth were centrifuged and the cells washed once with a solution containing $0.1 \mathrm{M} \mathrm{NaCl}, 10 \mathrm{~mm}$ Tris$\mathrm{HCl}$ (pH 8) and $1 \mathrm{mM}$ EDTA (TES). The pellet was resuspended in $0.5 \mathrm{ml}$ of TES in a $1.5-\mathrm{ml}$ tube; $10 \mu \mathrm{l}$ of a solution of lysostaphin at a concentration of $1 \mathrm{mg} / \mathrm{ml}$ was added and incubated for $30 \mathrm{~min}$ at $37^{\circ} \mathrm{C}$. A $20-\mu \mathrm{l}$ volume of aqueous sodium dodecyl sulphate $10 \% \mathrm{w} / \mathrm{v}$ was then added and the mixture left for $30 \mathrm{~min}$ at room temperature. An equal volume of water-saturated phenol:chloroform $(1: 1, \mathrm{v}: \mathrm{v})$ was added; the mixtures were emulsified by shaking by hand for at least $5 \mathrm{~min}$, centrifuged for $2 \mathrm{~min}$ and the lower, organic, phase was discarded. Extraction was repeated once with the phenol:chloroform mixture and then twice with chloroform alone. The resulting aqueous layer was decanted and to it was added an equal volume of water-saturated phenol. This was mixed, then centrifuged for $2 \mathrm{~min}$. The upper aqueous layer was placed in a clean tube; the DNA was precipitated by adding an equal volume of propan2-ol, removed on a glass rod, and redissolved in a solution containing $10 \mathrm{~mm}$ Tris- $\mathrm{HCl}, \mathrm{pH} 8$, and $1 \mathrm{mM}$ EDTA (TE8). Spermidine and $\mathrm{NaCl}$ were added to give final concentrations of $0.1 \mathrm{mM}$ and $0.3 \mathrm{M}$ respectively. The DNA was re-precipitated with propan-2-ol and placed at $-20^{\circ} \mathrm{C}$ for $10 \mathrm{~min}$. After centrifugation for $2 \mathrm{~min}$, the DNA pellet was resuspended in $100 \mu \mathrm{l}$ of TE8. Samples $(10 \mu \mathrm{l})$ were cleaved with 5-10 units of $B g 1 \mathrm{II}$ (Northumbria Biologicals Ltd, Cramlington, Northumberland) overnight at $37^{\circ} \mathrm{C}$. The resulting fragments were separated by electrophoresis on an agarose $0.9 \% \mathrm{w} / \mathrm{v}$ gel at $100 \mathrm{~V}$. A 1-kb "ladder" (Gibco-BRL) served as a molecular size standard.

\section{Results}

\section{Plasmid analysis of London Hospital isolates}

The results are summarised in table I. All the gentamicin-resistant London Hospital isolates
Table I. Plasmid profiles of London Hospital isolates

\begin{tabular}{|c|c|c|c|c|}
\hline $\begin{array}{l}\text { Isolate } \\
\text { type }\end{array}$ & $\begin{array}{l}\text { Strain } \\
\text { no. }\end{array}$ & Resistant to & $\begin{array}{l}\text { Plasmid } \\
\text { content } \\
\text { (kb size) }\end{array}$ & $\begin{array}{c}\text { Resistance(s) } \\
\text { lost when } \\
\text { plasmid } \\
\text { cured }\end{array}$ \\
\hline \multirow[t]{5}{*}{ MRSA } & 1 & PEDTMG & $>20$ & G \\
\hline & 2 & PEDTM C & 4.5 & na \\
\hline & 3 & PEDTMG & $>20$ & $\mathrm{G}$ \\
\hline & 4 & PEDTM C & $4 \cdot 5$ & $\mathrm{C}$ \\
\hline & 5 & PEDTMG & $>20$ & G \\
\hline \multirow[t]{5}{*}{ ORSA } & 6 & PET G N & $>20$ & na \\
\hline & 7 & PET & $2.8,3.8$ & $\mathrm{E}^{\mathrm{e} T}$ \\
\hline & 8 & PG & $>20$ & G \\
\hline & 9 & PE & $2 \cdot 8$ & \\
\hline & 10 & PE & $2 \cdot 8$ & $E^{e}$ \\
\hline \multirow[t]{5}{*}{ SSA } & 11 & $\mathbf{P}$ & Nil & $\ldots$ \\
\hline & 12 & $\mathbf{P}$ & Nil & $\ldots$ \\
\hline & 13 & $\mathbf{P}$ & Nil & $\ldots$ \\
\hline & 14 & $\mathbf{P}$ & Nil & $\ldots$ \\
\hline & 15 & $\mathbf{P}$ & Nil & $\ldots$ \\
\hline MRSA & 17 & PEDT Mi G & $>20$ & G \\
\hline ox & 19 & & Nil & $\ldots$ \\
\hline
\end{tabular}

$\mathrm{P}=$ benzylpenicillin,$\quad \mathrm{E}=$ erythromycin, $\mathrm{D}=$ clindamycin, $\mathrm{T}=$ tetracycline,$\quad \mathrm{M}=$ methicillin, $\quad \mathrm{G}=$ gentamicin, $\mathrm{C}=$ chloramphenicol, $\mathrm{N}=$ neomycin, $\mathrm{F}=$ fucidin; na=curing not achieved, $\ldots=$ curing not undertaken, $\mathrm{e}=$ ethidium bromide used to cure; $i=$ methicillin $\mathrm{MIC} 4 \mathrm{mg} / \mathrm{L}$.

(three MRSA, one intermediate MRSA, two ORSA) carried a large plasmid greater than $20 \mathrm{~kb}$. None of these plasmids was distinguishable by size. The two isolates resistant to chloramphenicol (both MRSA) carried plasmids of $4.5 \mathrm{~kb}$. Other plasmids were not detected in MRSA isolates. Three of the four ORSA isolates resistant to erythromycin carried a $2 \cdot 8-\mathrm{kb}$ plasmid, while one of the two tetracycline-resistant ORSA isolates carried a 3.8$\mathrm{kb}$ plasmid. Plasmids were not detected in the five SSA isolates nor in the "Oxford" strain of $S$. aureus.

When curing experiments were undertaken to establish which resistance markers were carried by each plasmid type, loss of resistance to gentamicin always correlated with loss of the plasmid greater than $20 \mathrm{~kb}$, to chloramphenicol with loss of the 4.5$\mathrm{kb}$ plasmid (fig. 1), and to tetracycline with loss of the $3 \cdot 8-\mathrm{kb}$ plasmid from isolates which carried it. All other parental resistance markers were retained by plasmid-free progeny. Incubation of isolate no. 7 at $43^{\circ} \mathrm{C}$ did not result in loss of resistance to erythromycin but, after incubation at $37^{\circ} \mathrm{C}$ in the presence of ethidium bromide, erythromycin-sensitive colonies which had lost the $2 \cdot 8-\mathrm{kb}$ plasmid 


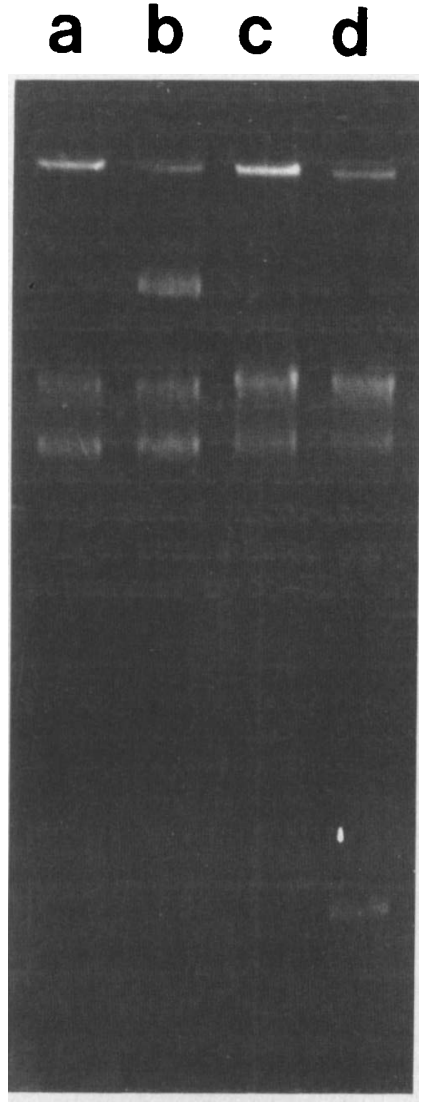

Fig. 1. Plasmid profiles of two London Hospital isolates before and after curing of antibiotic resistance: $\mathbf{a}$, cured isolate no. 3 sensitive to gentamicin; b, isolate no. 3 (parent); c, cured isolate no. 4 sensitive to chloramphenicol; d, isolate no. 4 (parent).

were obtained. Cured progeny of isolate no. 6 were not obtained.

\section{Plasmid analysis of isolates from other hospitals}

Plasmid carriage by MRSA isolates from other hospitals was assessed; the results are summarised in table II. Of the seven EMRSA isolates defined by phage typing, two were resistant to chloramphenicol and carried a plasmid of $4.5 \mathrm{~kb}$ indistinguishable by size from the equivalent London Hospital plasmid; four other isolates had plasmids of $2.4 \mathrm{~kb}$, probably corresponding to the "cryptic" plasmid described by Townsend et al. (1987). Many of the non-epidemic MRSA isolates carried one or more plasmids of various sizes, only some of which may correspond to those found in London Hospital isolates. These plasmids were not investigated further.
Table II. Plasmid profiles of other isolates

\begin{tabular}{cll}
\hline $\begin{array}{c}\text { Isolate type and } \\
\text { (strain) }\end{array}$ & Resistant to & $\begin{array}{c}\text { Plasmid content } \\
\text { (kb size) }\end{array}$ \\
\hline EMRSA(M) & P E D T M & $2 \cdot 4$ \\
(N) & P E D T M & $2 \cdot 4$ \\
(O) & P E D T M & Nil \\
(P) & P E D T M F & $2 \cdot 4$ \\
(R) & P E D T M C & $4 \cdot 5$ \\
(S) & P E D T M & $2 \cdot 4$ \\
(U) & P E D T M C & 4.5 \\
OMRSA (C) & P T M & $>20,4 \cdot 1,2 \cdot 4$ \\
(D) & P M & $>20,3,2 \cdot 4$ \\
(E) & P E T M & $>20$ \\
(F) & P E T M F N & $>20$ \\
(H) & P E T M & Nil \\
(I) & P E T M F C N & $>20,3 \cdot 2$ \\
(J) & P E T M F N N & $>20,4 \cdot 5$ \\
(K) & P E T M F G & $>20,2 \cdot 4$ \\
(L) & P M & $>20$ \\
& & \\
\hline
\end{tabular}

Abbreviations as in table I.

\section{Restriction enzyme site analysis of chromosomal DNA}

To test the value of restriction enzyme digests in characterising different strains of $S$. aureus, chromosomal DNA was prepared and digested with $E c o R I$ and $B g 1$ II. Because, in preliminary experiments a simpler banding pattern was obtained with $B g l$ II, this enzyme was used in subsequent analyses. To analyse DNA from London Hospital isolates, plasmid-free or cured strains were used. DNA from MRSA isolates nos. 1, 3, 4 and 5 and from isolate no. 17 (which has intermediate resistance to methicillin) gave identical sets of resolvable bands when digested with $B g$ III; examples are shown in fig. 2 . When DNA from five non-MRSA clinical isolates and the "Oxford" strain of $S$. aureus was analysed, each gave a pattern distinctly different from that of any other isolate (fig. 3). Of 20-30 resolvable fragments from each DNA sample, a few bands only of the same size were held in common.

DNA extracted from five EMRSA isolates from other hospitals in the Thames regions was next examined. All had the same set of restriction fragments as DNA from the London Hospital MRSA isolates (fig. 4); some carried small plasmids giving two extra but indistinct bands migrating between the 1- and 2-kb linear markers. Digests of DNA from non-epidemic MRSA isolates from other hospitals outside the Thames regions each had recognisable and distinct patterns, clearly different from that of EMRSA and from each other (fig. 5). However, these analyses were less satisfac- 

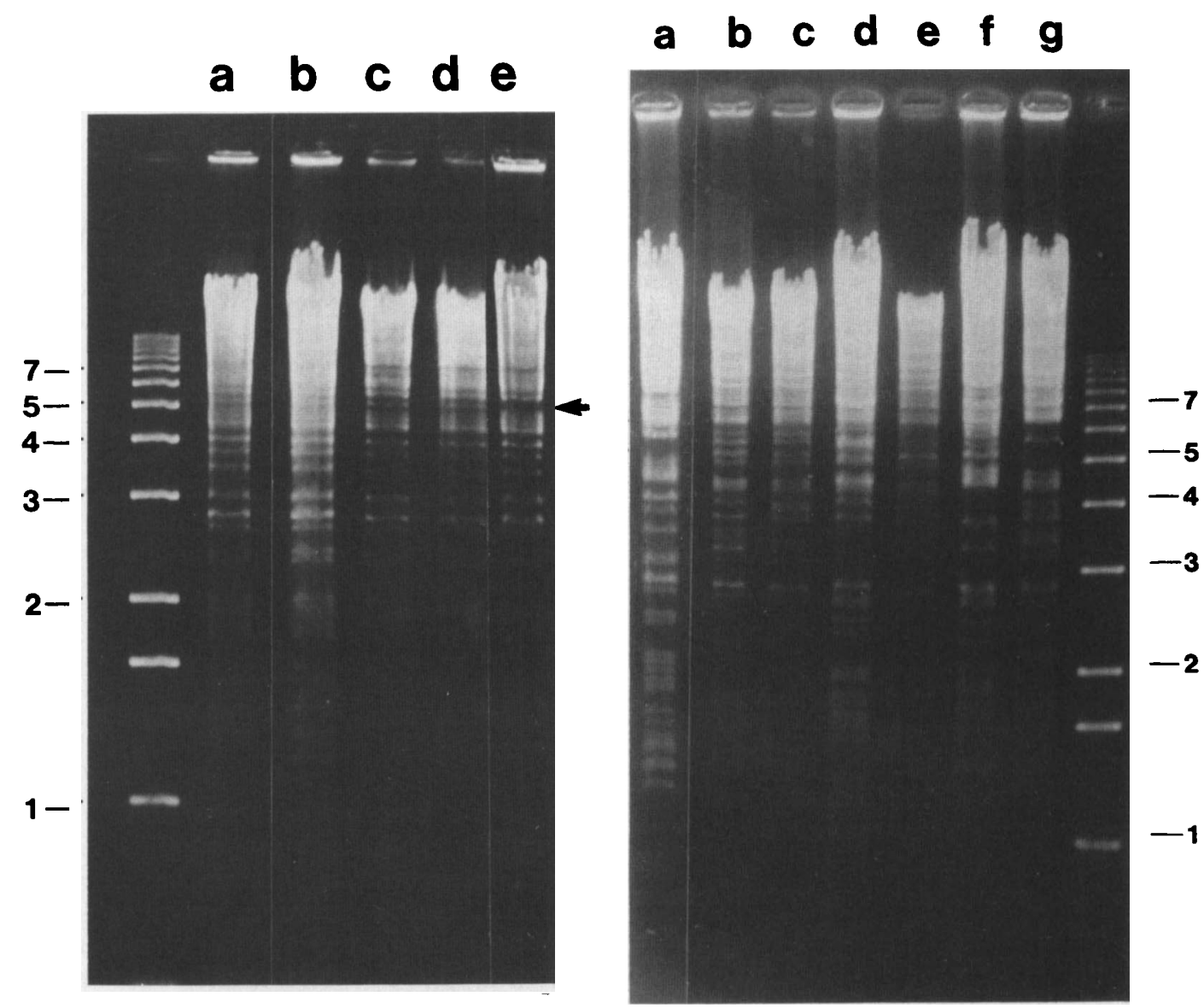

Figs. 2 (left) and 3. Restriction fragments of chromosomal DNA after digestion with $B g l$ II endonuclease and separation on $0.9 \%$ agarose, with size markers (in kb). Isolates were cured of any plasmids carried. 2: MRSA isolates from the London Hospital and Bethnal Green: a, isolate no. 17 (intermediate methicillin resistance); b, isolate no. 4; c, isolate no. 3; d, isolate no. 1; e, Bethnal Green isolate with position of missing band arrowed. 3: Methicillin sensitive isolates from the London Hospital: a, Bethnal Green MRSA isolate for comparison; $b$, isolate no. 13 ; $c$, isolate no. 11 ; d, isolate no. 10 ; $\mathbf{e}$, isolate no. 8; $\mathbf{f}$, isolate no. 7; $g$, 19, the "Oxford" staphylococcus.

tory because of the presence of plasmids in these isolates.

DNA from four isolates from an outbreak of staphylococcal infection at Bethnal Green Hospital were also examined. Their restriction patterns were identical, but differed by one band from the pattern of London Hospital MRSA isolates (fig. 2).

\section{Discussion}

Of the several methods of typing strains of $S$. aureus, phage typing is most widely used and is generally helpful. However, an increasing number of MRSA isolates from the Thames regions are non-typable with the standard international set of phages and experimental phages are required to define EMRSA (Marples et al., 1986).

Electrophoresis of ${ }^{35} \mathrm{~S}$-methionine-labelled pro- teins on SDS-polyacrylamide gel (Stephenson et al., 1986), immunoblotting of culture supernates (Krikler et al., 1986) and immunoblotting of whole cell extracts (Lee and Burnie, 1988) have recently been used to "fingerprint" isolates of $S$. aureus. Although these techniques appear to be effective, they identify proteins, the production of which is likely to be modified by cultural conditions. It would be preferable to be able to "fingerprint" the DNA of isolates.

Genetic analysis of antibiotic resistance has been useful when comparing clinical isolates of MRSA; Australian isolates have been particularly well studied by this method (Townsend et al., 1983; Lyon et al., 1984).

In the present study, analysis of the genetic basis of antibiotic resistance of a series of clinical isolates from the London Hospital, including MRSA and 


\section{a b c d e}

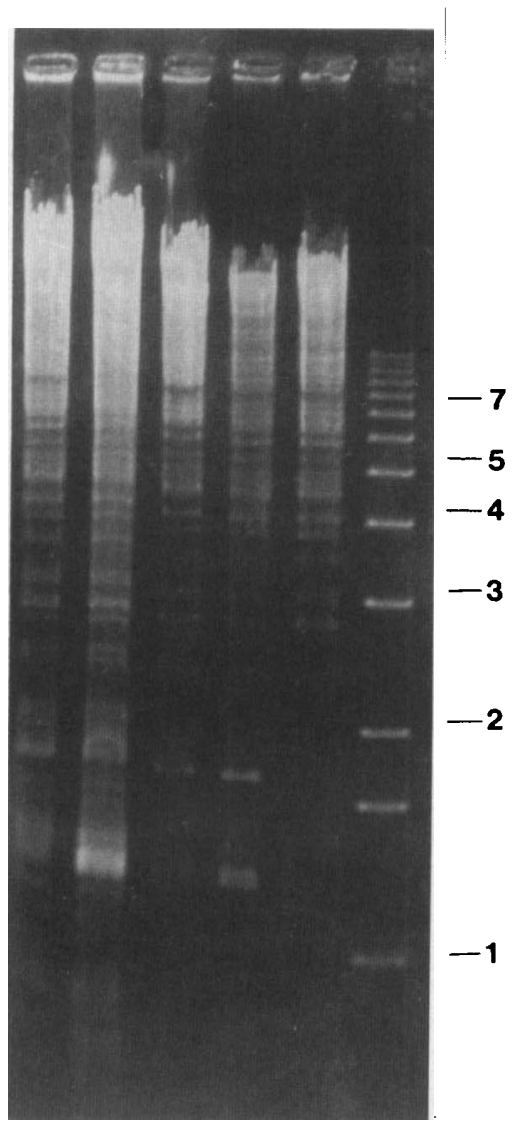

\section{a b c d e}

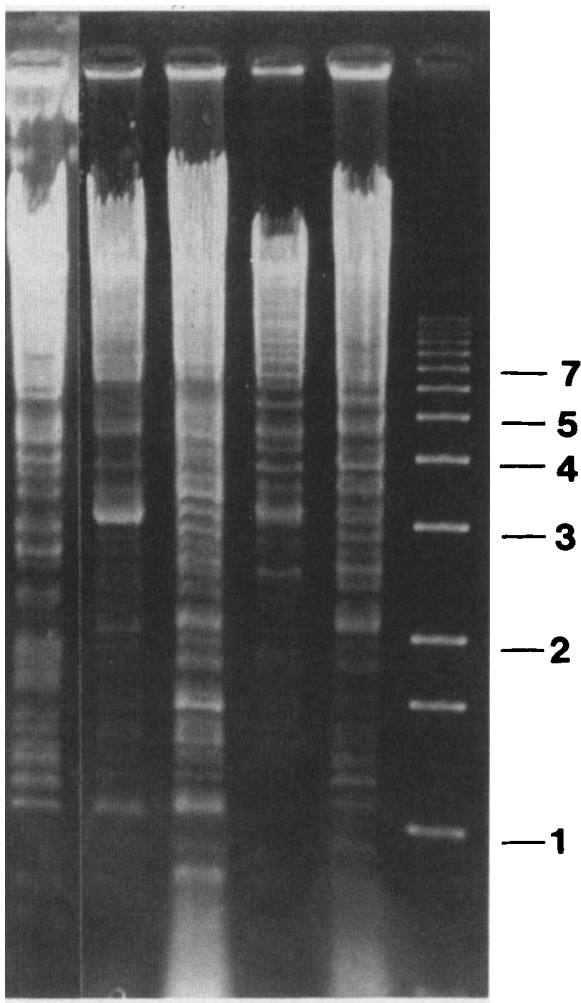

Figs. 4 (left) and 5. Restriction fragments of chromosomal DNA as figure 2, from uncured strains. 4: Epidemic MRSA isolates obtained from PHLS: a, isolate $S$; b, isolate $P$; $c$, isolate $N$; d, isolate $M$; e, isolate no. 5 (cured) from the London Hospital for comparison. 5: Other MRSA isolates from PHLS: a, Bethnal Green MRSA isolate for comparison; b, isolate C; c, isolate K; d, isolate $\mathrm{J} ; \mathbf{e}$, isolate $\mathrm{I}$.

strains sensitive to methicillin, has shown that MRSA isolates have chromosomal determinants encoding resistance to benzylpenicillin, erythromycin, clindamycin, tetracycline and methicillin, and carry plasmids, encoding gentamicin or chloramphenicol resistance, similar in size to those found in Australian MRSA isolates (Townsend et al., 1987). A gentamicin-resistance plasmid of the same size as that in MRSA was detected among methicillin sensitive isolates (ORSA), as were smaller plasmids encoding tetracycline or erythromycin resistance. One isolate, resistant to erythromycin and tetracycline (as well as to gentamicin and neomycin) did not carry small plasmids and is believed to carry these markers on the chromosome, but failure to cure a large plasmid thought to be responsible for gentamicin resistance prevented this from being confirmed. Dixson et al. (1984) noted that carriage of neomycin resistance inhibits the loss of gentamicin resistance.

Sixteen MRSA isolates from other hospitals in the UK were also examined for their plasmid content and antibiotic resistance. Seven strains, classified as EMRSA by phage typing, had patterns of resistance comparable to those of London Hospital isolates except that one was resistant to fucidin. Two chloramphenicol-resistant isolates had plasmids of the same size as those found in London Hospital isolates. Four of the seven EMRSA isolates carried a small plasmid, probably the cryptic plasmid described by Townsend et al. (1987). Non-epidemic MRSA isolates also had multiple resistance phenotypes, some of which could be distinguished from epidemic strains by a difference in inhibition pattern around a clindamycin disk only. It was not determined which 
resistances were chromosomally encoded except in isolate $\mathrm{H}$ which carried no detectable plasmids.

Although analyses of plasmids and antibiotic resistance provided some discrimination between groups of strains, we did not consider that individual isolates could be identified definitively by these characters. Plasmid carriage is inherently unstable; for example, different isolates of MRSA from the London Hospital carried different plasmids, and the same or similar plasmids were found in unrelated isolates. Also, the sets of chromosomal determinants in epidemic and non-epidemic MRSA may overlap.

An alternative method of characterisation is to digest chromosomal DNA with a restriction endonuclease and analyse the fragments produced. This technique has already been used to compare strains from a variety of bacterial species, e.g., Campylobacter pylori (Langenberg et al., 1986), BCG bacilli (Collins and de Lisle, 1987), Pseudomonas aeruginosa (Ogle et al., 1987) and others (Owen, 1984). In the present study, fragment patterns produced by digesting chromosomal DNA with the $B g l I I$ endonuclease proved to be very effective in discriminating between different isolates of $S$. aureus; methicillin-sensitive isolates each yielded a unique fragment pattern even when their antibioticresistance profiles were identical. By contrast, all of the London Hospital MRSA isolates examined had identical restriction patterns, and thus can be regarded as a single strain, even though they may carry different plasmids on different occasions. Interestingly, the single isolate with an intermediate level of resistance to methicillin also had the same restriction pattern and must be derived from the same parent strain, presumably having undergone a secondary mutation.

EMRSA isolates from other hospitals in London had the same restriction pattern as those from the London Hospital, whereas MRSA isolates classified as non-epidemic (i.e., with different and diverse phage types) each had a unique pattern. These results strongly support the view that the EMRSA isolates currently prevalent in the Thames region represent a single strain which is spreading within and between hospitals, whereas the other MRSA isolates examined seem to represent different strains with no common origin.

During the present study MRSA caused an outbreak of infection at Bethnal Green Hospital, within the same NHS district as the London Hospital; isolates were obtained from two clinical and two screening specimens. All four had the same DNA restriction fragment pattern, which was identical to that of the London Hospital MRSA isolates except for the lack of a single band. We conclude that the outbreak was due to EMRSA, and that the isolates have a common source, but that they may not have come directly from the London Hospital.

Analysis of chromosomal DNA restriction fragment patterns has, therefore, proved to be very useful in characterising and studying the spread of different MRSA and, because chromosomal DNA is analysed, the pattern of fragments produced is much more stable than plasmid profiles.

We thank Dr R. Marples for phage-typing and for providing isolates C-U, Dr G. Duckworth and Dr A. Hay for the isolates from the London and Bethnal Green Hospitals, and Dr R. Williams for support and helpful comments.

\section{REFERENCES}

Barber, M 1961 Methicillin-resistant staphylococci. Journal of Clinical Pathology 14: 385-393.

Bennett P M, Heritage J, Hawkey P M 1986 An ultra-rapid method for the study of antibiotic plasmids. Journal of Antimicrobial Chemotherapy 18 : 421-424.

Collins D M, de Lisle G W 1987 BCG identification by DNA restriction fragment patterns. Journal of General Microbiology 133: 1431-1434.

Dixson S, Brumfitt W, Hamilton-Miller J M T 1984 Stability of aminoglycoside resistance in vitro in gentamicin-resistant Staphylococcus aureus. Journal of Hygiene 93: 43-49.

Jevons MP 1961 Celbenin-resistant staphylococci. British Medical Journal 1: 124-125.

King K, Harvey K 1985 MRSA revisited. Medical Journal of Australia 142: 88-89.

Krikler S J, Pennington T H, Petrie D 1986 Typing of strains of Staphylococcus aureus by Western blot analysis of culture supernates. Journal of Medical Microbiology 21 : 169-171.

Langenberg W, Rauws, E A J, Widjojokusumo A, Tytgat G N J,

Zanen H C 1986 Identification of Campylobacter pyloridis isolates by restriction endonuclease DNA analysis. Journal of Clinical Microbiology 24: 414-417.

Lee W, Burnie J P 1988 Fingerprinting methicillin-resistant Staphylococcus aureus by the immunoblot technique. Journal of Medical Microbiology 25: 261-268.

Lyon B R, Iuorio J L, May J W, Skurray R A 1984 Molecular epidemiology of multiresistant Staphylococcus aureus in Australian hospitals. Journal of Medical Microbiology 17: 78-79.

Marples R R, Richardson J F, de Saxe M J 1986 Bacteriological characters of strains of Staphylococcus aureus submitted to a reference laboratory related to methicillin resistance. Journal of Hygiene 96: 217-223.

Ogle J W, Janda J M, Woods D E, Vasil M L 1987 Characterization and use of a DNA probe as an epidemiological marker for Pseudomonas aeruginosa. Journal of Infectious Diseases 155: 119-126.

Owen R J 1984 Nucleic acid sequencing and fingerprinting in bacterial classification. In: Sanna A, Morace G (eds) New horizons in microbiology. Elsevier, Amsterdam, pp 21-31. 
Stephenson J R, Crook S J, Tabaqchali S 1986 New method for typing Staphylococcus aureus resistant to methicillin based on sulphur-35 methionine labelled proteins: its application in an outbreak. British Medical Journal 293: 581-583.

Townsend D E, Grubb W B, Ashdown N 1983 Genetics of drug resistance in methicillin-resistant Staphylococcus aureus from Australian hospitals. Journal of Hospital Infection 4: 331-337.
Townsend D E, Ashdown N, Bradley J M, Pearman J W, Grubb W B 1984 "Australian" methicillin-resistant Staphylococcus aureus in a London hospital? Medical Journal of Australia 141 : $339-340$.

Townsend D E et al. 1987 The international spread of methicillin-resistant Staphylococcus aureus. Journal of Hospital Infection 9: 60-71. 